mắc động kinh là 539/100.000 dân, tỷ lệ mắc mới là 108/100.000 dân. Nhóm tuổi 10-19 mắc động kinh nhiêu nhất, động kinh không rõ nguyên nhân chiếm đa số, nguyên nhân động kinh thường gặp nhất là đột quị não. Loại cơn động kinh thường gặp là động kinh toàn thể.

\section{TÀl LIẸU THAM KHẢO}

1. Nguyễn Văn Doanh. (2007). Nghiên cứu một số đắc điểm dịch tễ học và điêu trị động kinh ở cộng đồng dân cư thuộc huyện Gia Bình tỉnh Bắc Ninht.

2. Dương Huy Hoà̃ng. (2009). Nghiên cứu một số đặc điểm dịch tễ, lâm sàng động kinh, tình hình quản lý bệnh nhân động kinh tại tỉnh Thái Bình. Luân án Tiến sĩ Y hoc năm 2009.

3. Nguyển Thúy Hường. (2001). Nghiên cứu một sổ đặc điểm dịch tễ và tình hình điều trị động kinh taai cộng đồng tỉnh Hà Tây, Luận án Tiến sĩ Y học, Học viện Quân y.

4. Nguyến Văn Hướng. (2003). Dịch tễ động kinh tại xã Phù Linh, huyện Sóc Sơn, Hà Nội, Luận văn Bác sĩ Đại học Y Hà Nội.

5. Nguyến Anh Tuấn. (2007). Tỷ lệ động kinh ở huyên Ba Vì.

6. Beghi E, Hesdorffer D (2014). Prevalence of epilepsy an unknown quantity. Epilepsia. 2014 Jul; 55(7): 963-7.

7. Fiest KM, Sauro KM, Wiebe S, Patten SB, Kwon CS, Dykeman J, et al (2017). Prevalence and incidence of epilepsy: A systematic review and meta-analysis of international studies. Neurology. 2017 Jan; 88(3): 296-303.

8. Mohammad Q D, Saha N C (2020). Prevalence of epilepsy in Bangladesh: Results from a national household survey. 5 (4), 526-536.

\title{
ĐĂC ĐIỂM LÂM SÀNG VÀ HUYẾT HOC THEO GEN ĐÔ̂T BIẾN CỦA BÊ̂NH NHI THALASSEMIA TẠI BỆNH VIỆN TRẺ EM HẢI PHÒNG
}

\author{
Đỗ Thị Quỳnh Mai*, Nguyễn Ngọc Sáng**, Bạch Thị Như Quỳnh**
}

\section{TÓM TẮT}

Mục tiêu: Mô tả đặc điểm lâm sàng và huyết học theo đột biến gen phổ biến của bệnh thalassemia ở trẻ em. Đối tượng: 83 bệnh nhi Thalassemia điều trị tại bệnh viện Trẻ em Hải Phòng từ 01/01/2015 đển $31 / 12 / 2020$. Phương pháp: Nghiên cứu mô tả một loạt ca bệnh. Kết quả: Biểu hiên lâm sàng thể athalassemia chủ yếu ở đột biến HbCs - SEA, HbCs và SEA - C2.delT. Bệnh nhi a-thalassemia thiếu máu nhe và trung bình ( $\mathrm{Hb}$ trung bình đột biến 1 gen là $93,8 \pm 10,4 \mathrm{~g} / \mathrm{l} ; 2$ gen là $92,4 \pm 13,5 \mathrm{~g} / \mathrm{l}$ và 3 gen là $87,2 \pm 8,5 \mathrm{~g} / \mathrm{l})$. Tỉ lệ HbA1giảm nhe $(83,9-94,2 \%), \mathrm{HbA} 2$ bình thường, $\mathrm{HbH}$ tăng (từ $7,8 \pm 2,5 \%$ đến $11,6 \pm 7,3 \%)$. Các triệu chứng ở bệnh nhi $\beta$ thalassemia biểu hiện ở thể $\beta^{0} \beta^{0}(100 \%)$ và $\beta^{0} \beta^{E}$ $(76,6 \%-96,2 \%)$, ít hơn ở thể $\beta^{0} \beta(9,5 \%-33,3 \%)$. Bệnh nhi $\beta$-thalassemia thiếu máu từ trung bình ( $\mathrm{Hb}$ trung bình thể $\beta^{0} \beta^{0}$ là $68,2 \pm 12,5 \mathrm{~g} / \mathrm{l}$ và $\beta^{0} \beta^{\mathrm{E}}$ là $79,8 \pm 14,2 \mathrm{~g} / \mathrm{l})$ đến nhẹ $(101,7 \pm 15,2 \mathrm{~g} / \mathrm{l})$. Thành phân $\mathrm{Hb}$ thay đối: Thể $\beta^{0} \beta^{0}, \mathrm{HbA} 1$ giảm $(35,7 \pm 12,2 \%), \mathrm{HbF}$ tăng $(60,8 \pm 23,7 \%) ;$ Thể $\beta^{0} \beta^{E}$ có $\mathrm{HbA} 1$ giảm $(26,1 \pm 14,1 \%) ; \mathrm{HbF}$ tăng $(38,5 \pm 14,6 \%)$ và $\mathrm{HbE}$ tăng $(38,3 \pm 15,7 \%) ;$ Đột biến $\beta^{0} \beta$, có HbA1 giảm $(73,7 \pm 26,5 \%) ; \quad H b \dot{2} 2$ tăng $(3,8 \pm 1,5 \%)$ và $\mathrm{HbF}$ tăng $(21,2 \pm 4,3 \%)$. Kết luận: a-thalassemia ít biểu hiện trên lâm sàng. Huyết học thay đổi tùy số gen tổn thương. Đăc trưng điện di $\mathrm{Hb}$ với tî lệ $\mathrm{HbH}$ tăng. Lâm sàng và chỉ số huyết học của bệnh nhân $\beta$-thalassemia

*Bệnh viện Trẻ Em Hải Phòng

**Trường Đai họ Y Dược Hải Phòng

Chịu trách nhiệm chính: Đố Thị Quỳnh Mai

Email: quynhmaikid@gmail.com

Ngày nhận bài: 14.9.2021

Ngày phản biên khoa học: 4.11 .2021

Ngày duyệt bài: 16.11.2021 thay đổi nhiều ở $\beta^{0} \beta^{0}$ và $\beta^{0} \beta^{E}$ hơn $\beta^{0} \beta$. Thành phần $\mathrm{Hb}$ thay đổi với $\mathrm{HbA}$ giảm, tăng cao $\mathrm{HbF}$ và có thể xuất hiên $\mathrm{HbE}$. Có sự liên quan giữa kiểu gen đột biến và kiểu hình ở bệnh nhi thalassemia.

Tư khóa: Thalassemia, đột biến gen, trẻ em.

\section{SUMMARY}

CLINICAL AND HEMATOLOGICAL

CHARACTERISTICS ACCORDING TO GENE MUTATIONS OF THALASSEMIA IN CHILDREN AT HAI PHONG CHILDREN'S HOSPITAL

Objectives: To describe clinical and hematological characteristics according to gene mutations of thalassemia in children. Subjects: 83 Thalassemia pediatric patients treated at Haiphong Children's Hospital from January 1, 2015, to December 31, 2020. Methods: Case-series study. Results: Clinical manifestations of a-thalassemia are mainly in HbCs SEA, HbCs and SEA - C2.delT mutations. Pediatric athalassemia mild-moderate anemia (mean $\mathrm{Hb}$ mutation of 1 gene: $93.8 \pm 10.4 \mathrm{~g} / \mathrm{l} ; 2$ genes: $92.4 \pm 13.5 \mathrm{~g} / \mathrm{l}$ and 3 genes: $87.2 \pm 8.5 \mathrm{~g} / \mathrm{l})$. The rate of HbA1 decreased slightly $(83.9-94.2 \%), \mathrm{HbA} 2$ was normal, $\mathrm{HbH}$ increased (from $7.8 \pm 2.5 \%$ to $11.6 \pm 7.3 \%)$. Symptoms in children with $\beta$-thalassemia were expressed in $\beta^{0} \beta^{0}(100 \%)$ and $\beta^{0} \beta^{E}(76.6 \%$ $96.2 \%)$, less so in $\beta^{0} \beta(9.5 \%-33.3 \%)$. Pediatric $\beta$ thalassemia anemia ranged from moderate (mean $\mathrm{Hb}$ of $\beta^{0} \beta^{0}$ body was $68.2 \pm 12.5 \mathrm{~g} / \mathrm{l}$ and $\beta^{0} \beta^{\mathrm{E}}$ was $79.8 \pm 14.2 \mathrm{~g} / \mathrm{l})$ to mild $(101.7 \pm 15.2 \mathrm{~g}) \mathrm{ll})$. $\mathrm{Hb}$ composition changed: The $\beta^{0} \beta^{0}, \mathrm{HbA1}$ decreased $(35.7 \pm 12.2 \%)$, HbF increased $(60.8 \pm 23.7 \%)$; The $\beta^{0} \beta^{E}$ form has decreased $\mathrm{HbA1}(26.1 \pm 14.1 \%)$; $\mathrm{HbF}$ increased $(38.5 \pm 14.6 \%)$ and $\mathrm{HbE}$ increased $(38.3 \pm 15.7 \%) ;$ Mutant $\beta^{0} \beta$ with reduced HbA1 $(73.7 \pm 26.5 \%) ; \mathrm{HbA} 2$ increased $(3.8 \pm 1.5 \%)$ and $\mathrm{HbF}$ increased $(21.2 \pm 4.3 \%)$. Conclusion: a-thalassemia 
rarely manifests clinically. Hematology varies according to the number of genes involved. Characterization of hemoglobin electrophoresis with increased $\mathrm{HbH}$ ratio. Clinical and hematological parameters of $\beta$-thalassemia patients changed more in $\beta^{0} \beta^{0}$ and $\beta^{0} \beta^{\mathrm{E}}$ than in $\beta^{0} \beta$. The hemoglobin composition changed with decreased $\mathrm{HbA}$, elevated $\mathrm{HbF}$ and possibly $\mathrm{HbE}$. There was an association between mutant genotype and phenotype in children with thalassemia.

Keywords: Thalassemia, genetic mutation, children.

\section{I. ĐĂT VẤN ĐỀ}

Thalassemia là một nhóm bệnh thiếu máu tan máu bẩm sinh do đột biến gen globin gây nên thiếu hụt tổng hợp một hay nhiều mạch polypeptid trong globin của hemoglobin. Lâm sàng bệnh thalassemia rất đa dạng, từ thể không có biểu hiện lâm sàng đến thể nặng phải truyền máu. Về huyết học, thường có sự biến đổi từ nhẹ đến nặng, khá đặc hiệu cho từng thể bệnh.

Hiện nay, các nghiên cứu về thalassemia chủ yếu tập trung mô tả về dịch tễ học ở một số khu vực, địa phương, lâm sàng, huyết học. Các nghiên cứu về đột biến gen globin gây bệnh thalassemia ở người Việt Nam còn ít. Vậy mối liên quan giữa đột biến gen với lâm sàng, huyết học của các thể bệnh thalassemia như thế nào? Để trả lời câu hỏi trên, chúng tôi tiến hành đề tài này nhằm mục tiêu: Mô tả đặc điểm lâm sàng và huyết học theo gen đột biến của bệnh nhi thalassemia điêu trị tại Bệnh viện Trẻ em Hải Phòng giai đoạn 2015 - 2020.

\section{II. ĐỐI TƯợNG VÀ PHƯƠNG PHÁP NGHIÊN CứU \\ 2.1. Đối tượng và thời gian nghiên cứu}

Đối tượng nghiên cứu gồm 83 trẻ Thalassemia điều trị tại bệnh viện Trẻ em Hải Phòng từ 01/01/2015 đến 31/12/2020.

Tiêu chuấn lựa chon: Bệnh nhi đủ tiêu chuẩn chẩn đoán xác định bệnh Thalassemia [1], [2].

\subsection{Phương pháp nghiên cứu}

- Thiết kế nghiên cứu: Mô tả một loạt ca bệnh.

- Cõ̃ mẫu và cách chọn mẫu: Lấy mẫu theo phương pháp thuận tiện, tất cả bệnh nhi thalassemia vào điều trị tại bệnh viện Trẻ em Hải Phòng trong khoảng thời gian nghiên cứu đều được lựa chọn vào nghiên cứu.

- Nội dung nghiên cứu:

+ Đặc điểm lâm sàng: thiếu máu, vàng da, gan lách to, biến dạng xương, sạm da, bộ mặt thalassemia,... theo đột biến gen ở bệnh nhi thalassemia.

+ Đặc điểm huyết học: Số lượng hồng cầu, nồng độ hemoglobin $(\mathrm{Hb})$, hematocrit, $\mathrm{MCH}$, $M C V, M C H C$, RWD, điện di huyết sắc tố ( $H b A 1$, $\mathrm{HbA2}, \mathrm{HbF}, \mathrm{HbE}, \mathrm{HbH}$ ) theo từng loại đột biến gen ở bệnh nhi thalassemia.

- Phương pháp thu thập số liệu: Mỗi bệnh nhân có một bệnh án theo mẫu nghiên cứu, trong đó ghi chép đầy đủ các số liệu về lâm sàng và huyết học.

- Xử lý số liệu theo phần mềm SPSS 26.0.

- Đạo đức nghiên cứu: Tất cả bệnh nhân, người nhà bệnh nhi đều đồng ý tham gia nghiên cứu. Đề tài đã được Hội đồng đạo đức $y$ sinh học Trường Đại học Y Dược Hải Phòng và bệnh viện Trẻ em Hải Phòng chấp thuận.

\section{KẾT QUẢ NGHIÊN CỨU}

3.1. Đặc điểm chung. Trong 83 bệnh nhi, có $56 \beta$-thalassemia và 27 a-thalassemia. Biểu hiện lâm sàng gặp chủ yếu ở bệnh nhi $\beta$ thalassemia. Có sự khác biệt có ý nghĩa thống kê $(p<0,05)$ về lâm sàng: thiểu máu, vàng $d a$, sạm da, biến dạng xương, số lần truyền máu/năm, phụ thuộc truyền máu giữa 2 nhóm athalassemia và $\beta$-thalassemia.

Các chỉ số RBC, HCT, MCV, MCH, MCHC, Ferritin, Fe huyết thanh, GOT, GPT có sự khác biệt có ý nghĩa thống kê $(p<0,05)$ giữa 2 nhóm bệnh nhân.

3.2. Đặc điểm lâm sàng, huyết học theo kiểu gen đột biến

3.2.1. Lâm sàng, huyết học của bệnh nhi a-thalassemia

Bảng 1. Đặc điểm lâm sàng theo kiểu gen đột biến ở bệnh nhi a-thalassemia(n=27)

\begin{tabular}{|c|c|c|c|c|c|c|}
\hline $\begin{array}{c}\text { Gen đột } \\
\text { biến }\end{array}$ & Vàng da & Thiếu máu & Lách to & Gan to & Biến dạng xương & Sạm da \\
\cline { 2 - 6 } & $\mathrm{n}(\%)$ & $\mathrm{n}(\%)$ & $\mathrm{n}(\%)$ & $\mathrm{n}(\%)$ & $\mathrm{n}(\%)$ & $\mathrm{n}(\%)$ \\
\hline 3.7 & $0(0,0)$ & $0(0,0)$ & $0(0,0)$ & $0(0,0)$ & $0(0,0)$ & $0(0,0)$ \\
\hline $3.7-\mathrm{SEA}$ & $0(0,0)$ & $0(0,0)$ & $1(33,3)$ & $1(33,3)$ & $0(0,0)$ & $0(0,0)$ \\
\hline $\mathrm{C} 2$ deIT & $0(0,0)$ & $0(0,0)$ & $0(0,0)$ & $0(0,0)$ & $0(0,0)$ & $0(0,0)$ \\
\hline $\mathrm{HbCS}$ & $0(0,0)$ & $1(50,0)$ & $1(50,0)$ & $1(50,0)$ & $1(50,0)$ & $1(50,0)$ \\
\hline $\mathrm{HbCs}-\mathrm{SEA}$ & $0(0,0)$ & $7(77,8)$ & $8(88,9)$ & $8(88,9)$ & $3(33,3)$ & $3(33,3)$ \\
\hline SEA & $0(0,0)$ & $2(22,2)$ & $4(44,4)$ & $4(44,4)$ & $1(11,1)$ & $0(0,0)$ \\
\hline SEA- C2.deIT & $1(50,0)$ & $1(50,0)$ & $1(50,0)$ & $2(100,0)$ & $1(50,0)$ & $1(50,0)$ \\
\hline
\end{tabular}

Bảng 1 cho thấy biếu hiê̂n lâm sàng nhiều ở trẻ mang đột biến $\mathrm{HbCs}$ và SEA (đơn đợt biên hay phối hợp). 
Bảng 2. Đặc điểm huyết học theo số lượng gen đột biến ( $n=27)$

\begin{tabular}{|c|c|c|c|}
\hline $\begin{array}{c}\text { Đặc điểm huyết } \\
\text { học }\end{array}$ & Tốn thương 1 gen & Tổn thương 2 gen & Tổn thương 3 gen \\
\cline { 2 - 4 } & $\overline{\mathrm{X}} \pm \mathrm{SD}$ & $\overline{\mathrm{X}} \pm \mathrm{SD}$ & $\overline{\mathrm{X}} \pm \mathrm{SD}$ \\
\hline $\mathrm{HC}\left(10^{12} / \mathrm{l}\right)$ & $5,14 \pm 0,41$ & $4,70 \pm 1,12$ & $4,29 \pm 0,96$ \\
\hline $\mathrm{Hb}(\mathrm{g} / \mathrm{dl})$ & $93,8 \pm 10,4$ & $92,4 \pm 13,5$ & $87,2 \pm 8,5$ \\
\hline $\mathrm{Hct}(\%)$ & $30,6 \pm 3,5$ & $29,5 \pm 4,0$ & $29,4 \pm 2,8$ \\
\hline $\mathrm{MCV}(\mathrm{fl})$ & $60,4 \pm 1,7$ & $64,7 \pm 10,8$ & $67,7 \pm 7,8$ \\
\hline $\mathrm{MCH}(\mathrm{pg})$ & $18,6 \pm 1,7$ & $20,3 \pm 4,1$ & $20,7 \pm 2,9$ \\
\hline $\mathrm{MCHC}(\mathrm{g} / \mathrm{dl})$ & $303,2 \pm 12,4$ & $313,2 \pm 13,5$ & $305,1 \pm 16,3$ \\
\hline $\mathrm{RDW}(\%)$ & $19,6 \pm 1,98$ & $20,7 \pm 6,2$ & $21,2 \pm 2,2$ \\
\hline
\end{tabular}

Bảng 2 cho thây các bệnh nhi a-thalassemia có thiếu máu từ nhẹ đến vừa. Tất cả các nhóm đều có $M C V<80 f l$, MCH <27pg, MCHC giảm, RDW lớn.

Bảng 3. Đặc điểm điện di huyết sắc tố theo số lượng gen a đột biến(n=27)

\begin{tabular}{|c|c|c|c|}
\hline \multirow{2}{*}{ Điện di Hb } & Tốn thương 1 gen & Tốn thương 2 gen & Tốn thương 3 gen \\
\cline { 2 - 4 } & $\overline{\mathrm{X}} \pm \mathrm{SD}$ & $\overline{\mathrm{X}} \pm \mathrm{SD}$ & $\overline{\mathrm{X}} \pm \mathrm{SD}$ \\
\hline $\mathrm{HbH}$ & $7,8 \pm 2,5$ & $11,6 \pm 7,3$ & $11,4 \pm 5,5$ \\
\hline $\mathrm{HbA} 1$ & $94,2 \pm 4,6$ & $88,8 \pm 7,8$ & $83,9 \pm 14,8$ \\
\hline $\mathrm{HbA} 2$ & $1,8 \pm 0,2$ & $1,7 \pm 0,3$ & $1,7 \pm 0,3$ \\
\hline
\end{tabular}

Bảng 3 cho thấy bệnh nhi a-thalassemia có tỉ lệ HbA1giảm nhẹ, HbA2 bình thường, có sự xuất hiện của $\mathrm{HbH}$.

3.2.2. Lâm sàng, huyết học của bệnh nhi $\beta$-thalassemia

Bảng 4. Đặc điểm lâm sàng theo kiểu đột biến gen HBB của $\beta$-thalassemia $(n=56)$

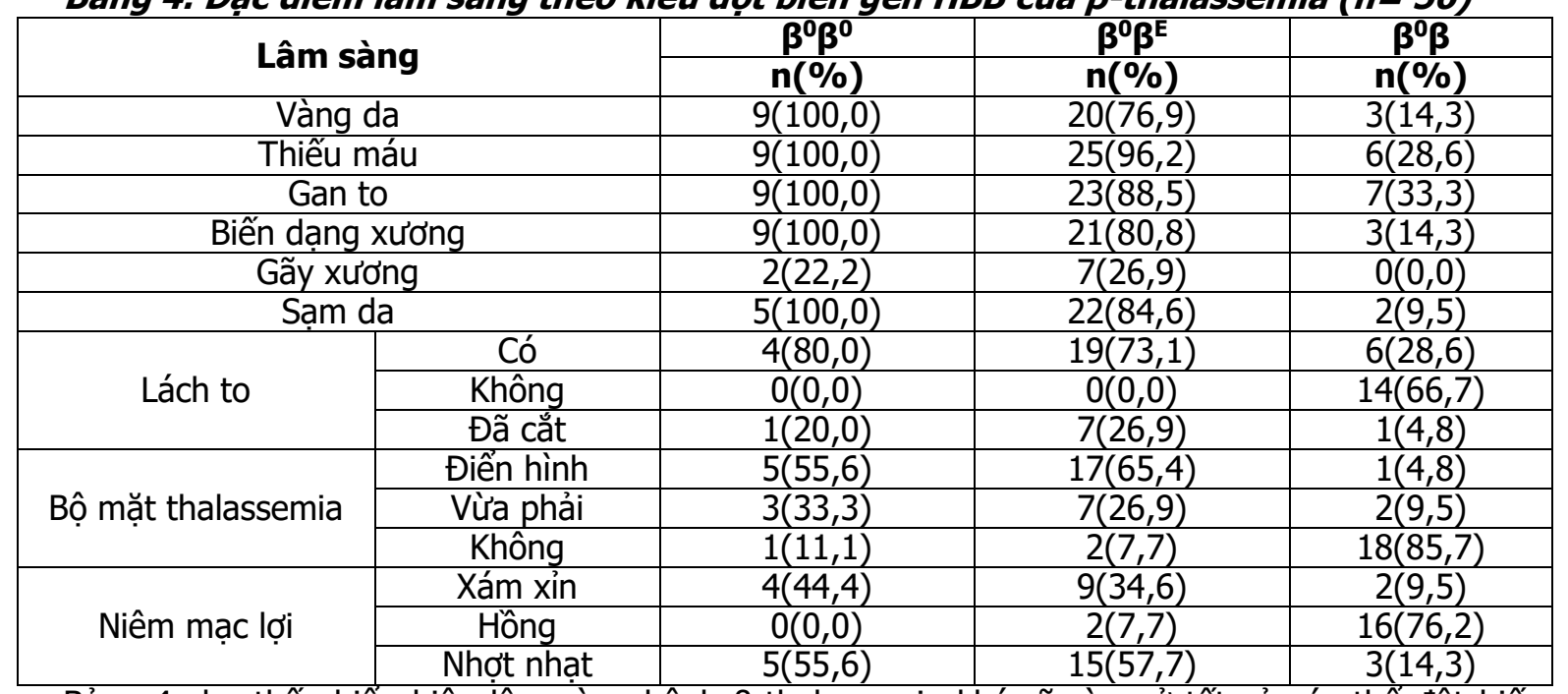

Bảng 4 cho thấy biêu hiện lâm sàng bệnh $\beta$-thalassemia khá rõ ràng ở tất cả các thế đột biến. Điển hình ở các bệnh nhân thể $\beta^{0} \beta^{0}$ và $\beta^{0} \beta^{E}$ hơn thể $\beta^{0} \beta$.

\begin{tabular}{|c|c|c|c|}
\hline \multirow{2}{*}{ Công thức máu } & $\beta^{0} \beta^{0}$ & $\beta^{0} \beta^{\mathrm{E}}$ & $\boldsymbol{\beta}^{0} \boldsymbol{\beta}$ \\
\hline & $\overline{\mathrm{X}} \pm \mathrm{SD}$ & $\overline{\mathrm{X}} \pm \mathrm{SD}$ & $\overline{\mathrm{X}} \pm \mathrm{SD}$ \\
\hline $\mathrm{HC}(\mathrm{T} / \mathrm{L})$ & $2,56 \pm 0,52$ & $3,53 \pm 0,56$ & $5,01 \pm 1,1$ \\
\hline $\mathrm{Hb}(\mathrm{g} / \mathrm{dL})$ & $68,2 \pm 12,5$ & $79,8 \pm 14,2$ & $101,7 \pm 15,2$ \\
\hline Hct (\%) & $19,2 \pm 4,8$ & $25,2 \pm 4,2$ & $32,2 \pm 5,1$ \\
\hline MCV (fl) & $78,4 \pm 7,5$ & $71,1 \pm 7,3$ & $65,1 \pm 8,1$ \\
\hline $\mathrm{MCH}(\mathrm{pg})$ & $26,8 \pm 2,7$ & $22,9 \pm 2,7$ & $20,7 \pm 2,9$ \\
\hline $\mathrm{MCHC}(\mathrm{g} / \mathrm{dl})$ & $342,0 \pm 14,8$ & $323,3 \pm 19,8$ & $319,6 \pm 18,9$ \\
\hline RDW (\%) & $19,6 \pm 5,4$ & $29,5 \pm 8,8$ & $20,5 \pm 6,6$ \\
\hline
\end{tabular}

Bảng 5 cho thấy các thế đột biến $\beta$-thalassemia đều có thiếu máu, mức độ từ trung bình đến nhẹ. Hồng cầu nhỏ nhược sắc tất cả bệnh nhân ( $\mathrm{MCV}<80 \mathrm{fl}, \mathrm{MCH}<27 \mathrm{pg})$. 
Bảng 6. Đặc điểm điện di Hb theo đột biến gen HBB của $\beta$-thalassemia(n= 56)

\begin{tabular}{|c|c|c|c|}
\hline \multirow{2}{*}{ Điện di Hb } & $\boldsymbol{\beta}^{\mathbf{0}} \boldsymbol{\beta}^{\mathbf{0}}$ & $\boldsymbol{\beta}^{\mathbf{0}} \boldsymbol{\beta}^{\mathbf{E}}$ & $\boldsymbol{\beta}^{\mathbf{0}} \boldsymbol{\beta}$ \\
\hline & $X \pm S D$ & $X^{\prime}$ & $X \pm S D$ \\
\hline$H \mathrm{HbA} 1$ & $35,7 \pm 12,2$ & $26,1 \pm 14,1$ & $73,7 \pm 26,5$ \\
\hline $\mathrm{HbA2}$ & $2,6 \pm 1,0$ & $3,7 \pm 2,7$ & $3,8 \pm 1,5$ \\
\hline $\mathrm{HbF}$ & $60,8 \pm 23,7$ & $38,5 \pm 14,6$ & $21,2 \pm 4,3$ \\
\hline $\mathrm{HbE}$ & & $38,3 \pm 15,7$ & \\
\hline
\end{tabular}

Bảng 6 cho thấy bệnh nhi $\beta$-thalassemia có tỉ lệ $\mathrm{HbA1}$ giảm, xuất hiện $\mathrm{HbF}$ với tỉ lệ cao. Thế $\beta^{0} \beta^{\mathrm{E}}$ có sự xuất hiện của Hbé.

\section{BÀN LUẬN}

- Về đặc điểm chung: Với 83 bệnh nhi thalassemia, có 27 a-thalassemia và $56 \beta$ thalassemia.

Biểu hiện lâm sàng của bệnh gặp chủ yếu ở bệnh nhi $\beta$-thalassemia, ít biểu hiện hơn ở bệnh nhi a-thalassemia. Có sự khác biệt có ý nghĩa thống kê $(p<0,05)$ về lâm sàng: thiếu máu, vàng $\mathrm{da}$, sạm da, biến dạng xương, số lần truyền máu/năm, phụ thuộc truyền máu giữa 2 nhóm athalassemia và $\beta$-thalassemia.

Các chỉ số huyết học (RBC, $\mathrm{HCT}, \mathrm{MCV}, \mathrm{MCH}$, $\mathrm{MCHC}$ ) và hóa sinh máu (Ferritin, Fe huyết thanh, GOT, GPT) đều có sự khác biệt có ý nghĩa thống kê $(p<0,05)$ giữa 2 nhóm a-thalassemia và $\beta$-thalassemia trong nghiên cứu của chúng tôi. Kết quả này khá tương đồng với các đề tài trước đây [3], [4], [5].

- Về biểu hiện lâm sàng và huyết học

\section{theo kiểu gen độtt biến}

+ Bệnh nhi a-thalassemia:

Hâuu hết bênh nhân a-thalassemia ít biểu hiện triệu chứng điển hình của bệnh. Các triệu chứng chủ yếu thây ở nhóm bệnh nhi mang đột biến HbCs và SEA (dạng đơn đột biến hay kết hợp). Có thể do đối tượng nghiên cứu của chúng tôi bao gồm cả những trẻ tình cờ phát hiện bệnh qua xét nghiệm, không hoặc chỉ có thiếu máu nhẹ. Như vậy, biểu hiện lâm sàng có liên quan đến mức độ nặng của bệnh.

Bệnh nhi a-thalassemia phần lớn có số lượng hồng câu trong giới hạn bình thường, nhưng lượng hemoglobin và hematocrit đều giảm ở tất cả các dạng đột biến. Những bệnh nhân tổn thương 1 gen và 2 gen có thiếu máu mức độ nhẹ ( $\mathrm{Hb}$ trung bình là $93,8 \pm 10,4 \mathrm{~g} / \mathrm{l}$ và $92,4 \pm 13,5 \mathrm{~g} / \mathrm{l})$. Trong khi những bệnh nhân mang 3 gen đột biến thiếu máu mức độ trung bình ( $\mathrm{Hb}$ trung bình là $87,2 \pm 8,5 \mathrm{~g} / \mathrm{l})$. Nồng độ hematocrit cũng có xu hướng giảm ở tất cả các bệnh nhân trong nhóm nghiên cứu. Như vậy, chúng tôi thấy rằng những bệnh nhân mang 3 gen tổn thương sẽ thiếu máu nhiều hơn nhóm trẻ có ít gen tổn thương. Kết quả của chúng tôi tương đồng với nghiên cứu trước đây [6]. Có thể do tan máu xảy ra từ từ, thiếu máu không xảy ra nhanh hay đột ngột nên bệnh nhân thường thích nghi được với tình trạng thiếu máu, rất ít trường hợp nhập viện do hemoglobin xuống quá thấp.

Tất cả các nhóm bệnh nhi a-thalassemia trong nghiên cứu của chúng tôi đều có $M C V$ giảm < 80fl, $\mathrm{MCH}$ thấp < 27pg. MCV giảm ở các nhóm tổn thương 1 gen $(60,4 \pm 1,7 \mathrm{fl}), 2$ gen $(64,7 \pm 10,8 \mathrm{fl})$, và 3 gen $(67,7 \pm 7,8 \mathrm{fl})$. $\mathrm{MCH}$ tương đồng giữa các nhóm. Như vậy, bệnh nhi athalassemia có hồng cầu nhỏ nhược sắc. Kết quả này phù hợp với các nghiên cứu trước đây [5], [7]

Điện di huyết sắc tố ở bệnh nhi $a-$ thalassemia, có tỉ lệ HbA1 giảm nhẹ, $\mathrm{HbA} 2$ bình thường và xuất hiện $\mathrm{HbH}$ (trung bình từ $7,8 \%$ đến $11,6 \%$ ). Bệnh nhi a-thalassemia có tổn thương gen a-globin làm giảm tổng hợp chuỗi $a$, dẫn đến thừa tương đối chuỗi $\beta$-globin, tạo nên $\mathrm{HbH}$. Vì thế, bệnh nhân a-thalassemia có tỷ lệ $\mathrm{HbH}$ cao hơn bình thường. Kết quả của chúng tôi phù hợp với nghiên cứu trước đó [8]

\section{+ Bệnh nhi $\beta$-thalassemia:}

Trong 56 bệnh nhi $\beta$-thalassemia, chúng tôi phát hiện ra 86 alen đột biến tổ hợp được 7 loại đột biến gen. Từ đó, hình thành được 3 kiểu gen $\beta^{0} \beta^{0}, \beta^{0} \beta^{\mathrm{E}}$ và $\beta^{0} \beta$.

Biểu hiện lâm sàng của bệnh nhi $\beta$ thalassemia khá rõ ràng ở tất cả các thể đột biến. Hầu hết các bệnh nhi mang đột biến thể $\beta^{0} \beta^{0}$ và $\beta^{0} \beta^{E}$ có biểu hiện lâm sàng điển hình như thiếu máu, vàng da, biến dạng xương, bộ mặt thalassemia, sạm da, niêm mạc lợi/ nhợt nhạt, gan to, lách to hoặc đã cắt lách. Các bệnh nhân mang đột biến dị hợp tử đơn $\beta^{0} \beta$ biểu hiện ít rõ ràng hơn.

Thiếu máu ở $\beta$-thalassemia thường xảy ra khá sớm. Gần $100 \%$ các trẻ mang đột biến $\beta$ thalassemia thể $\beta^{0} \beta^{0}$ và $\beta^{0} \beta^{\mathrm{E}}$ vào viện có thiếu máu. Thiếu máu ít gặp ở trẻ có đột biến thể dị hợp đơn hơn. Triệu chứng lách to biểu hiện của tan máu mạn tính, nhiêu trường hợp cường lách phải cắt lách. Tất cả bệnh nhân mang đột biến $\beta^{0} \beta^{0}$ và $\beta^{0} \beta^{E}$ đều có lách to với tỉ lệ cắt lách khoảng $20 \%$. Trong khi, $66,7 \%$ thể $\beta^{0} \beta$ không có lách to. Một nghiên cứu trước có kết quả tương 
tự với chúng tôi [3].

Như vậy, triệu chứng lâm sàng của bệnh $\beta$ thalassemia rất đa dạng và biểu hiện khá tương tự như nhau ở tất cả các thể đột biến, chỉ khác nhau về các mức độ biểu hiện từ trung bình đến nặng. Như vậy, có sự liên quan rõ ràng giữa kiểu gen - kiểu hình lẩm sàng của bệnh nhi $\beta$ thalassemia. Nhận xét này của chúng tôi phù hợp với nghiên cứu trước đây [3].

Có sự biến đổi về chỉ số huyết học khá đặc hiệu ở bệnh nhi $\beta$-thalassemia. Các bệnh nhi $\beta$ thalassemia thể $\beta^{0} \beta^{0} \quad(\mathrm{Hb}$ trung bình: $68,2 \pm 12,5 \mathrm{~g} / \mathrm{l})$ thiếu máu nặng hơn bệnh nhi thể $\beta$-thalassemia/HbE $(68,2 \pm 12,5 \mathrm{~g} / \mathrm{l})$ và $\beta^{0} \beta$ $(101,7 \pm 15,2 \mathrm{~g} / \mathrm{l})$. Số lượng hồng cầu và hematocrit cũng có sự giảm tương ứng. Bên cạnh đó, các chỉ số hồng cầu khác như $\mathrm{MCV}$, $\mathrm{MCH}, \mathrm{MCHC}$, RDW thay đổi rất có ý nghĩa. Thể tích trung bình hồng cầu MCV giảm (trung bình là $70.0 \pm 8,8 \mathrm{fl})$, giảm nhiều nhất ở thể $\beta^{0} \beta$ $(65,1 \pm 8,07 f \mathrm{f})$, sau đó là $\beta^{0} \beta^{\mathrm{E}}(71,1 \pm 7,3 \mathrm{fl})$ và $\beta^{0} \beta^{0}(78,4 \pm 7,5 f 1)$. Có sự giảm rõ của $\mathrm{MCH}<$ $28 \mathrm{pg}$ ơ tất cả các trẻ $\beta$-thalassemia $(23,4 \pm 5,2 \mathrm{pg})$, tương đương nhau ở các thể. MCHC trong giới hạn bình thường. RDW lớn ở các nhóm đối tượng $\beta$-thalassemia, dao động từ $19,6 \pm 5,4$ (thể $\beta^{0} \beta^{0}$ ) đến $29,5 \pm 8,8$ (thể $\beta^{0} \beta^{\mathrm{E}}$ ). Như vậy, đặc điểm về hồng câu trong $\beta$ thalassemia là nhiều hồng cầu nhỏ, hồng cầu nhược sắc nặng, kích thước hồng cầu không đều, to nhỏ rất khác nhau. Các chỉ số này thường được sử dụng để chẩn đoán sàng lọc thalassemia nói chung và các thể bệnh thalassemia nói riêng.

Thành phần hemoglobin ở bệnh nhi $\beta$ thalassemia có sự thay đổi rất nhiều. Với bệnh nhân $\beta$-thalassemia, HbA1 giảm rõ (trung bình $46,6 \pm 34,3 \%) ; \mathrm{HbA} 2$ tăng nhẹ (trung bình là $3,6 \pm 1,9 \%) ; \quad \mathrm{HbF}$ tăng cao (trung bình $37,5 \pm 25,7 \%)$. Kết quả này tương tự nghiên cứu của Nguyễn Thị Thu Hà [8]. Tỉ lệ $\mathrm{HbA2}>3,5 \%$ là chỉ thị đặc trưng cho $\beta$-thalassemia ở người Việt Nam và nước ngoài [5]. Sự thay đổi về các thành phần huyết sắc tố thường được sử dụng làm tiêu chuẩn huyết học để chuẩn đoán sàng lọc và xác định bệnh $\beta$-thalassemia.

Thành phần hemoglobin thay đổi khá đặc hiệu cho các thể bệnh. Thể $\beta^{0} \beta^{0}, \mathrm{HbA} 1$ giảm $(35,7 \pm 12,2 \%)$, HbF tăng rất cao $(60,8 \pm 23,7 \%)$. Bệnh nhân $\beta$-thalassemia/HbE có HbA1 giảm nhiều $(26,1 \pm 4,1 \%) ; \quad \mathrm{HbF}$ tăng rất cao $(38,5 \pm 14,6 \%) ;$ HbA2 tăng nhe $(3,7 \pm 2,7 \%)$. Đặc biệt có sự xuất hiện nhiều HbE $(38,3 \pm 15,7 \%)$. Đột biến $\beta^{0} \beta$, có HbA1 giảm ít $(73,7 \pm 26,5 \%)$;
$\mathrm{HbA2}$ tăng nhẹ $(3,8 \pm 1,5 \%)$ và $\mathrm{HbF}$ tăng $(21,2 \pm 4,3 \%)$. Sự thay đổi thành phần hemoglobin ở các bệnh nhi của chúng tôi phù hợp với nghiên cứu trước đó [8].

\section{KẾT LUẬN}

Bệnh nhi a-thalassemia: Biểu hiện lâm sàng (thiếu máu, vàng da, gan lách to, biến dạng xương, gãy xương) chủ yếu thây ở nhóm bệnh nhi mang đột biến HbCs và SEA. Đa số các bệnh nhi a-thalassemia có thiếu máu mức độ nhẹ đến vừa và những bệnh nhi mang 3 gen tổn thương thiếu máu nhiều hơn. Chỉ số $\mathrm{MCV}, \mathrm{MCH}$ giảm ở tất cả các nhóm. Bệnh nhi a-thalassemia có thiếu máu từ nhe đến vừa và hồng cầu nhỏ nhược sắc. Tỉ lệ $\mathrm{HbA}$ igiảm nhẹ, $\mathrm{HbA2}$ bình thường, xuất hiện $\mathrm{HbH}$ (từ $7,8 \%$ đến $11,6 \%$ ).

Bệnh nhi $\beta$-thalassemia: Có 3 kiểu gen $\beta^{0} \beta^{0}$, $\beta^{0} \beta^{E}$ và $\beta^{0} \beta$ hình thành từ 7 dạng đột biến. Biểu hiện lâm sàng rõ ràng ở đột biến thể $\beta^{0} \beta^{0}$ và $\beta^{0} \beta^{E}$ hơn thể $\beta^{0} \beta$. Thể $\beta^{0} \beta^{0}$ thiếu máu nặng hơn thể $\beta$-thalassemia/HbE và $\beta^{0} \beta$. MCV giảm $<80 \mathrm{fl}$, nhiêu nhất ở thể $\beta^{0} \beta$, sau đó là $\beta^{0} \beta^{E}$ và $\beta^{0} \beta^{0}$. $\mathrm{MCH}<28 \mathrm{pg}$ và tương đương nhau ở các thể. Thành phân hemoglobin thay đổi khá đặc hiệu, đă̆c trưng là giảm tỉ lệ $\mathrm{HbA} 1$, tăng cao $\mathrm{HbF}$ và có thể xuất hiện $\mathrm{HbE}$ với tỉ lệ cao (thể $\beta^{0} \beta^{\mathrm{E}}$ ).

Có sự liên quan giữa kiểu gen đột biến và kiểu hình ở bệnh nhi thalassemia.

\section{TÀI LIẸU THAM KHẢO}

1. Shelth S (2017). Beta-thalassemia. BMJ best practice.

2. Shelth S (2017). Anpha-thalassemia. BMJ Best Practice.

3. Nguyễn Hoàng Nam (2019), Nghiên cứu kiểu hình và kiểu gen ở bệnh nhi beta-thalassemia, Luận án Tiến sĩ y học, Trường Đại học Y Hà Nội.

4. Phan Hùng Việt (2016). Nghiên cứu đặc điểm lâm sàng và xét nghiệm bệnh Thalassemia ở trẻ em tại khoa nhi Bệnh viện Trung ương Huế. Tạp Chí Dược Hoc - Trứ̛̀ng Đại Học Dược Huế, Tập 6, số 5-tháng i0/2016, 104-i10.

5. Ngô Diếm Ngọc (2017), Nghiên cứu đă̆c điểm lâm sàng, kiếu gen của bệnh $\mathrm{HbH}$ và chẩn đoán trước sinh bênh anpha-thalassemia, Luận văn Tiến sĩ y hơc, Trường Đai hơc $Y$ Hà Nội.

6. Nguyền Khắc Hân Hoan (2013), Nghiên cứu tầm soát và chẩn đoán trước sinh bệnh anphathalassemia và beta-thalassemia, Luận văn Tiến sĩ y học, Trường Đại học Y Dược Thành Phố Hồ Chí Minh.

7. Nguyễn Hoàng Nam, Lý Thị Thanh Hà, Dương Bá Trực và CS (2017). Đột biến gen ở bệnh nhân thalassemia tại bệnh viện Nhi Trung Ương. Tap Chí Nhi Khoa, 10(5), 46-51.

8. Nguyễn Thị Thu Hà (2017), Nghiên cứu đăc điểm đột biến gen globin và theo dôi điêu trị thải sắt ở bệnh nhân thalassemia tại Viện Huyết học Truyền máu Trung ương giai đoạn $2013-2016$, Luận văn Tiến sĩ y học, Trương Đại học Y Hà Nội. 